\title{
Analysis of Access to Credit and Agriculture Performance in Sub-Saharan Africa
}

\author{
Mustapha Abiodun Akinkunmi \\ Brickfield Road Associates Limited, Lagos, Nigeria
}

Email address:

maakinresearch@gmail.com

\section{To cite this article:}

Mustapha Abiodun Akinkunmi. Analysis of Access to Credit and Agriculture Performance in Sub-Saharan Africa. International Journal of Agricultural Economics. Vol. 2, No. 6, 2017, pp. 160-164. doi: 10.11648/j.ijae.20170206.11

Received: September 19, 2017; Accepted: September 29, 2017; Published: December 3, 2017

\begin{abstract}
This study examined the influence of access to credit on agriculture production in Sub-Saharan Africa. The nature and availability of panel dataset constrained the study to analyze its aim through a panel co-integration approach. The analysis was carried out for 21 selected African countries, over the period 2000-2014. The findings indicated evidence of long run relationship between agriculture production and total credit. The estimations strongly revealed that total credit to agriculture has a positive and significant influence on the level of agriculture production in the region.
\end{abstract}

Keywords: Access to Credit, Agriculture, Panel Co-Integration

\section{Introduction}

The upward trending of food imports in Sub-Saharan Africa, despite its huge fertile land, remains a great concern among the stakeholders. About 65 percent of the uncultivated arable land is abandoned and thus the continent spends nearly US $\$ 35$ billion on yearly basis to import food [1]. The utilization of these land resources will boost the global food supply in the future. The huge importation of food has adversely affected the value of their currencies, increased the inflation rate and triggered high youth unemployment especially in the rural areas. Owing to this, African government needs to put in place measures in order to optimally utilize its agricultural potentials. However, there is a strong need to understand why agricultural production remains low in the region. Studies such as [16, 18, 23-24]; postulated that the low yields in Sub-Saharan Africa are caused by the inability of farmers to purchase external inputs such as chemical fertilized, pesticides and seeds. The low use of these external inputs is attributed to credit constraints confronting the farmers. This study intends to provide answers to the following research questions: Does credit to agriculture improve the agriculture yields in the region? Does the impact differ between cash and food crops?

Therefore, the study conducts a fine-grained analysis of yield effects of agriculture's access to credit in Africa. In addition, it provides contexts for fully understanding the dynamics of agriculture output and credit access in the region. The existing-related studies are reviewed in the following section while methodology is presented in Section three. Empirical results are presented and discussed in Section Four. Section five concludes.

\section{Related Literature Review}

Prior to the 1990s, the government credit was the major source of finance for farmers engaging in the production of cereals and export cash crops. The measure resulted into fiscal deficits as farmers considered it as means of protection after harvests [24]. This led to its abolition in the 1990s and 2000s during Structural Adjustment. Government explored another channel to assist farmers through provision of subsidies to them in order to purchase fertilizers. The subsidy was provided in form of a reduction of fertilizer price or a coupon to farmers (as a direct transfer). Most subsidy schemes in the region were abolished by Structural Adjustment, while some African countries partially reviewed the scheme in the mid-2000s. For instance, Malawi and Tanzania government provide a coupon of an acre-sufficient fertilizer to many farmers, whereas Nigerian government utilized a reduction of fertilizer price.

Most of these government measures to assist farmers recorded low success due to the corrupt-environments of many African countries. Private-sector bank is used as a 
means which farmers can finance the external inputs. However, previous studies identified a limited credit to farmers through this channel $[24,25]$. This is as a result of high transaction costs, absence of collateral, and low recovery rate [9]. In addition, the work of [29] concluded that larger farmers in Cameroon, Ghana, Madagascar, and Malawi were only able to obtain bank credit. Another available source of finance to farmers is informal credit. This is obtained from friends and family and local moneylenders. This source provides huge funds for farmers to purchase inputs and consumption items [23, 29]. Furthermore, the tied output-credit or interlinked credit packages are another source of credit to farmers identified in [3, 24]. This deals with an output buyer or input seller that provides the input at the commencement of the season, and is reimbursed from the farmers' harvest. Two different views on tied output-credit arrangement are emanated. The first view confirms that processing or export companies make the arrangement with traditional export cash crops, while the other found that processing and export companies do not frequently apply because of lack of trust in farmers [27, 24, 25, 6]. Interlinked credit scheme is offered by grain wholesalers and input dealers, and is commonly practised in Asia and SSA [3, 8, 19, and 29].

Access to credit has been considered as a means through which farmers especially small-scale ones can alleviate poverty, boost agriculture productivity, and trigger the transition from subsistence farming to large-scale and agribusiness farming $[10,26,5,11]$. With the credit access, farmers can increase the use of external inputs as well as finance their operating expenses in the short-run, while in the long run, ability to make profitable investments is enhanced [8]. However, the low level of agriculture credit in the region is attributed to the dominance of the rural economy characterized with very low distribution of financial services. This study intends to examine how the private -bank credit influences agriculture yields in the sub-Saharan African region.

Agriculture still remains the significant backbone of the African economy, and accounts for more than 60 percent of jobs across the continent. However, the sector constitutes only 25 percent of its GDP, ranging from 3 percent of GDP in Botswana to nearly 50 percent in Chad, the Central Africa Republic, and Sierra Leone [1]. From 1990 till now, emerging countries witness a tremendous increase in their production cereals, for instance Brazil (164\%), Uruguay (81\%), Chile (96\%), and Malaysia (43\%). Whereas, the growth of cereal production in Africa records less than 40 percent on average in the same period. This is attributed to a relative underdevelopment of private sector infrastructure beyond production.

The successful business-led agriculture can be attained through the following: a large-scale dissemination of productivity-increasing technology and inputs, plus input intensity and capital intensity; designing input and output market structures as well as incentives to achieve the full potential production; and establishing a well-funded and competitive private sector that can drive long-term sustained growth agribusiness in the continent. In the light of this, this study aims to investigate the impact of credit on agriculture output in sub-Saharan Africa. In addition, it specifically provides an evidence-based framework for designing optimal means of utilizing private credit in transforming agriculture.

\section{Methodology}

The development of panel econometrics gives a room for the two-fold dimension, individual and temporal of the related data. Employing data observed for $\mathrm{N}$ entities over $\mathrm{T}$ periods provides the researcher a larger number of observations as well as the number of degrees of freedom. This minimizes the co-linearity among independent variables. In addition, the panel data models are appropriate to address the issue of missing or unobserved variables. Owing to inadequate data availability, the study is constrained to use two variables (Agriculture production and Credit) in performing its analysis.

\subsection{Equation Specification}

This study utilizes Panel Cointegration approach and Panel Fully Modified Least Squares (PFMLS) method to examine the role of total credit on agriculture output in selected African countries. The double log-linear equation can be specified as follows:

$$
\ln (\operatorname{Prod})_{i t}=\beta_{1}+\beta_{2} \ln (\text { Credit })_{i t}+\varepsilon_{t}
$$

Where Prod denotes agricultural production; Credit is total credit to agriculture; and $\varepsilon$ represents the error term. $\beta_{1}$ and $\varepsilon_{i t}$ denotes the intercept and the error term respectively. The slope parameter is represented by $\beta_{2}$ which is expected to be positive, as an increase in total credit to agriculture is supposed to lead to a rise in agriculture production.

\subsection{Panel Cointegration Approach}

The use of panel cointegration analysis is as a result of many factors like the dimension and characteristics of the data. The traditional panel techniques such as random effect, fixed effect, etc. are appropriate for data with small $\mathrm{T}$ and large $\mathrm{N}$ mainly observed in the microeconomic datasets obtained from the survey. However, panel data analysis with $\mathrm{T}>\mathrm{N}$ data might produce spurious results because the feature of the data behaviour tends to be close to time series. At macroeconomic level, the spuriousness increases as series in macro data are often non-stationary. [2] identifies two possible ways to address the problem generated by the accumulation of observation over time, namely: 1) heterogeneous regression for each individual to avoid the homogeneity of coefficients estimated with a single regression; and 2) the utilization of time series procedures to panels with the aim of dealing with nonstationarity and co-integrations among series. The panel cointegration is an extension of time series analysis to panel data with large T. Furthermore, its capacity to accommodate 
long run information is included in panels in order to allow the short-run dynamic and fixed effect to be heterogeneous across the panel. Short and long run estimates are possible in the panel co-integration [22]. The steps involved can be summarized as follows: the preliminary investigation is a unit root test. If a series were confirmed to be integrated, there is need to check the possible co-integration among variables by running a co-integration test. Finally, if there is existence of co-integration, put differently, if there is a long-run equilibrium among variables, one would estimate the long-run coefficients.

Two means of employing panel models are micro-panels (with a short time dimension and a very large number of entities) which are devoted to examine the behaviour of firms and households, and macro panels (similar time and individual dimensions) which are devoted to national and global economic growth. This study employs a macro-panel approach.

\section{Empirical Results and Discussions}

\subsection{Panel Unit Root}

Several approaches have been applied to test the order of integration of series in panel data. [17] extended the technique of the augmented Dickey-Fuller (ADF) with introduction of his panel unit root test. The Levin unit root test is specified as:

$$
\Delta y_{i t}=\phi_{i t} \psi_{i}+\rho y_{i t-1}+\sum_{j=1}^{n i} \varphi_{i j} \Delta y_{i, t-j}+\xi_{i t}
$$

Where $\phi_{i t}$ entails individual deterministic components like fixed effect, trend or a mixture of fixed effects and trend; $\rho$ represents the autoregressive coefficients; $\xi_{i t}$ is the error terms; and $\mathrm{n}$ denotes the lag order.
The LLC test makes assumption of the constant value for $\rho$ across panels; this may lead to loss of power [4]. Therefore, [13] corrected this assumption by allowing $\rho$ to change across panels:

$$
\Delta y_{i t}=\phi_{i t} \psi_{i}+\rho_{i} y_{i t-1}+\sum_{j=1}^{n i} \varphi_{i j} \Delta y_{i, t-j}+\xi_{i t}
$$

[4] addresses the issue of bias generated in applying LLC or IPS arising from the difference in size (between $\mathrm{N}$ and $\mathrm{T}$ because LLC and IPS are stronger when T is larger than N) or from the inclusion of an individual deterministic trend in the tests. However, the Fisher tests (ADF and PP) as noted by [7] apply the time series ADF and PP tests framework to panel data. The unique of this test is the combination of each series p-value generated from their unit root tests rather than the averaging individual test statistics. The [12] unit root technique depends on the Lagrangian multiplier and residuals obtained from individual ordinary least square regression on deterministic components to compute the statistics. In addition, Hadri tests unlike other tests are based on the homogeneity in the unit root process $\left(\rho_{i}=\rho\right)$ across the panels.

The panel unit root tests used in this study entail individual effects and the deterministic time trend. The Akaike information criterion (AIC) and the Schwann information criterion (SIC) are utilized to determine the optimal lag length. The shadowy estimation is based on Bartlett kernel and the bandwidth is determined by Newey and West automatic lag selection.

As presented in Table 1, the results indicate fair evidence of stationarity of the variable after taking the first difference. All the tests reject the null hypothesis of non-stationarity for both agricultural production and private credit variables. This suggests all the concerned variables are order of integration one i.e. I (1).

Table 1. Panel Unit Root Tests.

No effects

\begin{tabular}{llll}
\hline Series & Levin, Lin \& Chu t* & ADF - Fisher Chi-square & PP - Fisher Chi-square \\
\hline D(LNCREDIT) & $-9.38^{* * *}$ & $144.03^{* * *}$ & $237.78^{* * *}$ \\
D(LNPROD) & $-9.12^{* * *}$ & $151.20^{* * *}$ & $269.03^{* * *}$ \\
\hline
\end{tabular}

Individual effects

\begin{tabular}{llll}
\hline Series & Levin, Lin \& Chu t* & ADF - Fisher Chi-square & PP - Fisher Chi-square \\
\hline D(LNCREDIT) & $-4.92 * * *$ & $100.71 * * *$ & $220.37 * * *$ \\
D(LNPROD) & $-4.48 * * *$ & $100.45 * * *$ & $233.88 * * *$ \\
\hline
\end{tabular}

Individual effects, individual linear trends

\begin{tabular}{llll}
\hline Series & Levin, Lin \& Chu t* & ADF - Fisher Chi-square & PP - Fisher Chi-square \\
\hline D(LNCREDIT) & $-4.30 * * *$ & $72.51 * * *$ & $213.14 * * *$ \\
D(LNPROD) & $-2.45 * * *$ & $61.95 * *$ & $197.69 * * *$ \\
\hline
\end{tabular}

Note: $* * * * *$, and $*$ represent $1 \%, 5 \%$ and $10 \%$ respectively

\subsection{Co-integration Test}

The presence of I (1) in the series calls for the need to examine the long-run equilibrium among the variables. Three co-integration test approaches are employed to the variables of interest, namely [21] panel and group statistics, [15, 28] 
tests. Each test utilizes different methods and assumptions to compute statistics, with the null hypothesis of no cointegration among series, against the alternative that cointegration exists.

Pedroni panel tests rely on the within dimension analysis, and their statistics is computed through adding numerators and denominators along series independently. Its four components are panel v-statistic (a non-parametric test based on variances ratio), a panel-rho, panel-PP and panel ADF statistics that are equivalent to PP $\rho$ statistics, PP t-statistics, and ADF t-statistics in univariate time series respectively.

Kao t-statistics utilizes an ADF framework with the assumption of homogeneity in the panels. Its statistics is obtained from panel least squared dummy variable (LSDV) analysis. However, the Westerlund test provides four alternatives, Gt, Ga, Pt, and $\mathrm{Pa}$. The test applies an error correction model to investigate the presence of co-integration in individual panels or in the whole panel. By rejecting Ga and Gt null hypothesis indicates the existence of cointegration in at least one of the cross sections as the duo statistics utilizes individual weighted average process and individual t-statistics respectively. On the other hand, $\mathrm{Pa}$ and Pt employ a pooling process over cross-section, and the rejection of null hypothesis suggests that co-integration exists among variables in the panel as a whole.

Table 2. Panel Cointegration Test.

\begin{tabular}{llll}
\hline Hypothesized & Fisher Stat.* & Fisher Stat.* \\
\hline No. of CE(s) & (from trace test) & Prob. & (from max-eigen test) \\
None & 185.50 & 0.00 & 169.20 \\
At most 1 & 91.24 & 0.00 & 91.24 \\
\hline
\end{tabular}

Table 2 reports the outcomes of the co-integration tests based on Fisher approach. All these tests include none, individual intercept and trend. The finding suggests the evidence of a long-run relationship among variables. Put differently, variables are co-integrated. This indicates that the series tends to move together in the long run, and the difference between them is stationary.

\subsection{Estimation/Robustness}

Confirming that variables are co-integrated, the last stage is to estimate the link. In order to get more insights on the findings, the study carries out a short-run analysis. Furthermore, a series of robustness would aid the significance of the outcome. The common applied panel cointegration analyses are the dynamic OLS (DOLS) and the fully modified OLS (FMOLS).

The DOLS utilizes leads and lags of the first difference explanatory variables to estimate the long-run link among variables. In addition, its assumption of independence between cross sections is made. However, the test does not estimate the short-run parameter coefficients. In order to obtain the short-term estimates, the system GMM, the dynamic fixed effect (DFE), the Pooled mean Group (PMG) and the Mean Group (MG) estimators are utilized.

The system GMM addresses the puzzle of endogeneity by regarding each variable as endogenous, and instruments the variables by their own lag with the room of adding external instruments. However, the estimator is more efficient when $\mathrm{T}<\mathrm{N}$. DFE, MG and PMG are closely related. The DFE is based on the assumption that the slope of the co-integrating vectors and error variances are constant across panels. Put differently, all series are pooled, thus, making the slope parameter homogenous. Only intercepts are specific to each panel. The MG averages slopes across panels and the intercept. In addition, error variances are allowed to change across panels. In conclusion, the PMG is an intermediate between the MG and DFE by taking the average and pooling the coefficients across panels. The short-run coefficients are specific to each cross section, while the long run effect of the coefficients are limited to be homogenous across panels.

Results of the estimation including the robustness tests are reported in Table 3. The findings indicate that a $1 \%$ increment in total credit to agriculture, increases agriculture production by 0.17 percent. The output-effect of total credit to agriculture appears to be positive and significant with a $1 \%$ level. The positive influence of total credit on agriculture production is explained by the government measures put in place to stimulate the sector financially through the improved access to credit to the farmers. This supports the previous findings of $[16,18]$.

Table 3. Panel Fully Modified Least Squares (FMOLS).

\begin{tabular}{llll}
\hline Series & Coefficient & t-Statistic & Prob. \\
\hline Dependent Variable: LNPROD & 0.17 & 9.92 & 0.00 \\
LNCREDIT & 0.99 & & \\
Adjusted R-squared & & & \\
\hline
\end{tabular}

\section{Conclusion}

This study attempted to examine the impact of total credit to agriculture on the level of agricultural production in SubSaharan Africa. To achieve its aim, the analysis utilized a panel co-integration approach to estimate the short and long- run relationship among the concerned variables. Results indicate clear evidence that total credit significantly and positively influenced the level of agricultural production in the region. The policy implication of the findings is that government needs to stimulate the distribution of financial services in the rural areas where the agriculture is the 
mainstay of their economy. In addition, provision of relevant soft infrastructures that can enhance access to credit facilities for farmers, has to be made because the low level of agriculture performance in the region is attributed to inability of farmers to purchase external inputs. For instance, with 1 percent increased access to credit, the region's agriculture output rises about 17 percent.

\section{References}

[1] African Development Bank (2016). Feed Africa: Strategy for Agricultural Transformation in Africa, 2016-2025.

[2] Baltagi B. (2008). Econometric analysis of panel data, fourth edition. Chichester: John Wiley \& Sons; 2008.

[3] Bardhan, P. K., (1980). Interlocking factor markets and agrarian development: a review of issues. Oxford Economic Paper, 32(1), 82-98.

[4] Breitung J. (2000). The local power of some unit root tests for panel data. In: Baltagi B, editor. Nonstationary panels, panel cointegration, and dynamic panels, advances in econometrics, $15(1), 161-78$.

[5] Carter, M. R., and Olinto, P. (2003). Getting institutions "right" for whom? Credit constraints and the impact of property rights on the quantity and composition of investment. American Journal of Agricultural Economics, 85(1), 173-186.

[6] Chao-Béroff, R., (2014). Global dynamics in agricultural and rural economy, and its effects on rural finance. In: Finance for Food. Springer, 3-21.

[7] Choi I(2001). Unit root tests for panel data. Journal International Money Finance, 20(1), 249-72.

[8] Conning J., Udry C. (2007). Rural financial markets in developing countries. Handbook on Agricultural Economics, 3 (1), 2857-2908.

[9] Dorward A. R., Kirsten J. F., Omamo S. W., Poulton C., Vink N. (2009). Institutions and the agricultural development challenge in Africa. In: Kirsten J. F., Dorward A. F., Poulton C., Vink N., editors. Institutional Economics Perspectives on African Agricultural Development. IFPRI; Washington DC, 334.

[10] Feder, G., Lau, L. J., Lin, J. Y., and Luo, X. (1990). The relationship between credit and productivity in Chinese agriculture: A model of disequilibrium. American Journal of Agricultural Economics, 72(5), 1151-1157.

[11] Foltz, J. (2004). Credit Market access and profitability in Tunisian agriculture. Agricultural Economics, 30(3), 229-240.

[12] Hadri, K. (2000). Testing for stationarity in heterogeneous panel data. Econometrics Journal, 3 (2), 148- 161.

[13] Im K. S, Pesaran M. H, Shin Y. (2003). Testing for unit roots in heterogeneous panels. J Econ 115(53): 74.
[14] Kao, C. (1999). Spurious regression and residual-based tests for cointegration in panel data. J Econ 90: 1-44.

[15] Kao, C., Chiang M. H. (2000). On the estimation and inference of a cointegrated regression inpanel data. In: Baltagi BH, Fomby TB, Hill RC, editors. Nonstationary panels, panel cointegration, and dynamic panels, 15. Advanced in Econometrics: P. 170-222.

[16] Kelly, V., Adesina, A. A, Gordon, A. (2003). Expanding access to agricultural inputs in Africa: a review of recent market development experience. Food Pol. 28: 379-404.

[17] Levin, M., Lin, C. F, Chu, C. S (2002). Unit root tests in panel data: asymptotic and finite sample properties. J Econ 108: 124.

[18] Morris, M., Kelly, V. A., Kopicki, R. J. \& Byerlee, D. (2007). Fertilizer Use in African Agriculture: Lessons Learned and Good Practice Guidelines, Technical report, World Bank.

[19] Pearce, D., (2003). Buyer and supplier credit to farmers: do donors have a role to play? Paper presented at Paving the Way Forward for Rural Finance: An International Conference on Best Practices. Washington DC, June 2-4.

[20] Pedroni P. (1996) Fully Modified OLS for Heterogeneous Cointegrated Panels and the Case of Purchasing Power Parity. Department of Economics, Indiana University; 1996, [WP 96020].

[21] Pedroni P. (1999) Critical values for cointegration tests in heterogeneous panels with multiple regressors. Oxford Bulletin of Economics \& Statistics, 61(1), 653-670.

[22] Pedroni P. (2000) Fully modified OLS for heterogeneous cointegrated panels. Advances Econometrics, 15 (1), 93-130.

[23] Poulton C., Kydd J., Dorward, A. (2006). Overcoming market constraints on pro-poor agricultural growth in Sub-Saharan Africa. Dev. Pol. Rev., 24(3), 243-277.

[24] Poulton C., Dorward A., Kydd J. (1998). The revival of smallholder cash crops in Africa: public and private roles in the provision of finance. J. Int. Dev., 10(1): 85-103.

[25] Poulton C., Dorward A., Kydd J. (2010). The future of small farms: new directions for services, institutions, and intermediation. World Dev., 38(10), 1413-1428.

[26] Sial, M., and Carter, M. (1996). Financial market efficiency in agrarian economy: Microeconometric analysis of the Pakistani Punjab. The Journal of Development Studies, 32(5), 771-798.

[27] Shepherd A., Farolfi S. (1999). FAO; Rome, Export Crop Liberalization in Africa: A Review.

[28] Westerlund J. (2007) Testing for error correction in panel data. Oxford Bulletin of Economics \& Statistics, 69(6), 709-748.

[29] Zeller M., Sharma M. (1998). International Food Policy Research Institute; Washington, D. C., Rural Finance and Poverty Alleviation. Food Policy Report. 